Joschka Bischoff, Michal Maciejewski

\title{
Electric Taxis in Berlin - Analysis of the Feasibility of a Large-Scale Transition
}

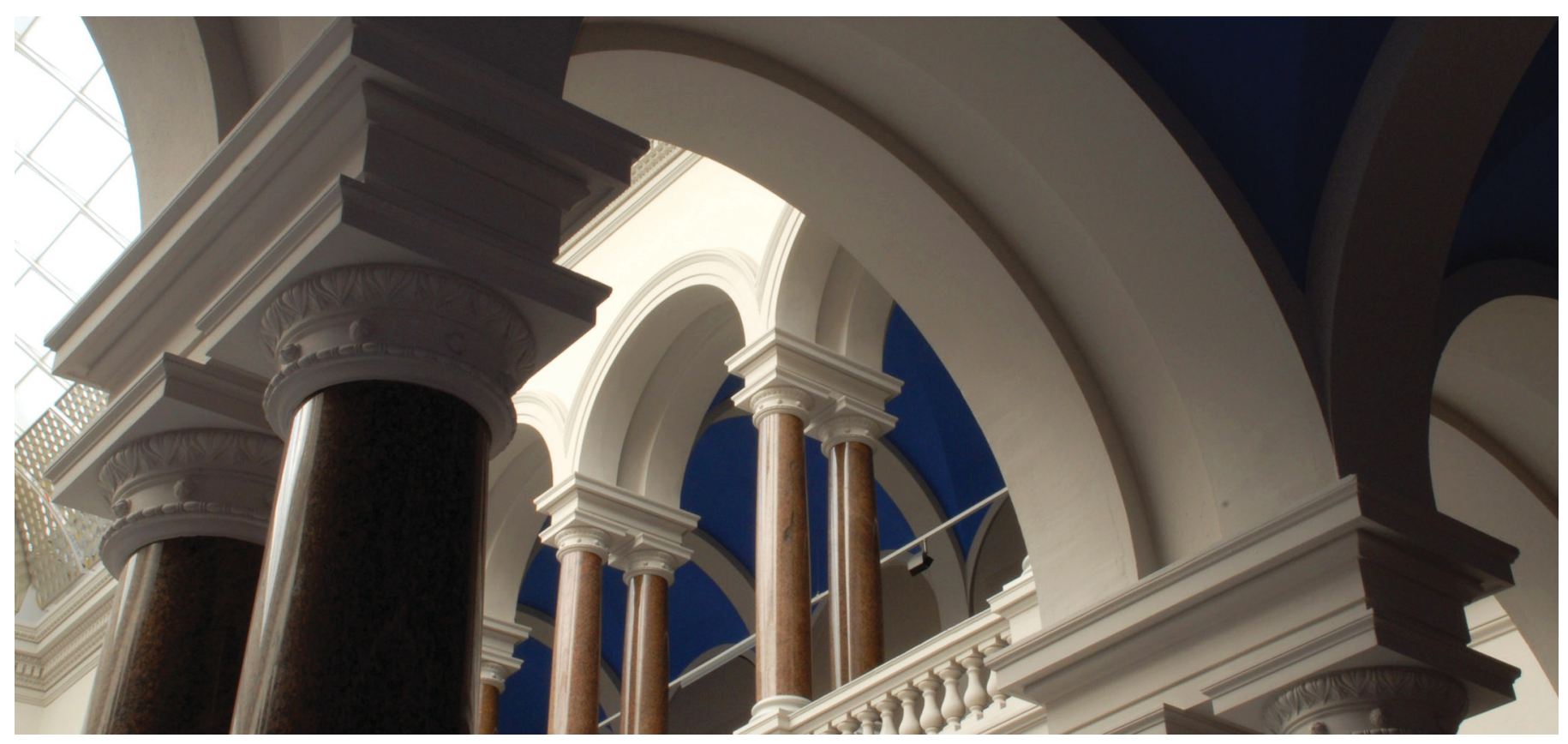

Bischoff, J.; Maciejewski, M. (2015). Electric Taxis in Berlin - Analysis of the Feasibility of a Large-Scale Transition. Tools of Transport Telematics, 343-351. https://doi.org/10.1007/978-3-319-24577-5_34 


\title{
Electric taxis in Berlin - Analysis of the feasibility of a large-scale transition
}

\author{
Joschka Bischoff $^{1}$, Michal Maciejewski ${ }^{1,2}$ \\ ${ }^{1}$ Technische Universität Berlin \\ Department of Transport Systems Planning and Transport Telematics \\ Berlin, Germany \\ \{bischoff, maciejewski\}@vsp.tu-berlin.de \\ ${ }^{2}$ Poznan University of Technology \\ Division of Transport Systems \\ Poznan, Poland \\ michal.maciejewski@put.poznan.pl
}

\begin{abstract}
Battery operated electric vehicles (BEVs) offer the opportunity of running a zero-emission car fleet. However, due to their current range constraints, electric vehicle operations are mainly attractive for inner-city transport, such as the taxi business. This paper is bringing together facts and assumptions about Berlin's taxi transport and the current conditions of BEVs in Germany to provide the scope of electrification. Firstly, the necessary amount of fast chargers is determined taking general constraints of Berlin's taxi business into account. For charging, especially busy days during cold winter days will be critical. Furthermore, a pricing scheme for fast charger usage is introduced. Based on this, operating operation costs of a hybrid electric vehicle and a battery electric vehicle are compared. The authors conclude that BEV operation will only pay off if the vehicle's battery life can be warrantied over a long span or costs of electric energy in Germany drops.
\end{abstract}

Keywords: Berlin, BEV, electric taxis, fast charging infrastructure, electric cars

\section{Introduction}

Battery electric vehicles (BEVs) are on the top list of currently discussed topics concerning private transport. Research in BEVs is driven both privately and by the public with huge investments. At the same time, however, the general public looks rather sceptical at electric cars. Especially, the short range is a restraint that prevents people from switching to BEVs. Therefore, it seems a plausible idea to evaluate BEVs in those fields of usage where the vehicle range is not of major importance. Inner city taxi services are one of them. Each single task is usually short so that the vehicle range does not prevent taxis from fulfilling single requests. On the other hand, the taxi overall daily mileage is comparably high, so that they would have to be re-charged at some time of the day. Moreover, the use of BEV as taxis has the potential to reduce inner city greenhouse gas emissions, especially since conventional taxis have relatively high share in these emissions. At the same time, taxis may be seen as a lighthouse project for BEV usage in general: Taxi passengers will gain the opportunity to try out an electric car on the passenger seat and some may get 
convinced to buy one at a later stage if they are satisfied with the quality of the electric taxi service.

This study aims to provide an overview about possible impacts of using BEV for Berlin's taxi business on a large scale. To provide a high quality service, there are several issues that have to be addressed prior to the introduction of electric taxis. Among them is the question of where and when taxi drivers should recharge their vehicles' batteries and how many chargers are needed to warrant a smooth service. With the Berlin taxi business being highly competitive, it is also of major importance to determine the impact of BEV usage the taxis' operating cost.

\section{Related work and current real-world appliance}

The usage of BEVs in taxi fleets has rapidly increased over the last years. In Europe, the biggest fleet has been announced to operate in Amsterdam using 167 Tesla Model S. ${ }^{1}$ Worldwide, Shenzhen has the largest fleet with roughly 1000 operative vehicles. ${ }^{2}$ Electric taxis may now also be found in regions with colder climate conditions, such as several cities in Estonia. ${ }^{3}$ Several authors see taxi operators as potential buyers of BEV [8].

For New York City, a large-scale feasibility study comes to the conclusion that BEV operations for one third of the city's yellow-taxi taxi fleet would require at least 300 fast chargers and cost 20 million \$ annually that could only partly be recovered by user costs [11]. The study also comes to the conclusion that one fast charging outlet is required per 13 taxis.

The authors have evaluated possibilities of electric taxis in smaller cities [3] using a microscopic simulation approach $[7,10]$. It could be shown that electric taxi operation works well under ordinary demand conditions, yet conventional powered taxi fleets are capable to serve sudden peaks in taxi demand better.

\section{General context}

Using BEV as taxis leads to some constraints that come both from the taxi business as such, as well as from the current state-of-the-art technology.

Currently, some 8000 taxi vehicles are licensed to operate in Berlin. These are operated by around 18000 taxi drivers [5]. Taxi fares are regulated by the city authority and mainly depend on distance rather than time. During a typical 8-hour shift, a taxi drives between 100 and $120 \mathrm{~km}$ in total and yields between 100 to $120 \mathrm{e}$ of metered fares. A recent study by the authors shows that under normal conditions taxis are idle (either standing at ranks or cruising) around 50 percent of their online time [4]. However, during trade fairs and similar events, yields and driving distances

\footnotetext{
1 see http://cleantechnica.com/2014/10/21/amsterdam-airport-enlists-167-tesla-taxis/

2 see http://www.tdm-beijing.org/files/news/Factsheet_GoodPracticeChina_ElectricTaxi_20130409.pdf

3 see http://www.elektritakso.ee/
} 
for part of the fleet may be twice as high, as it was the case during a railway strike in October 2014 [9].

In contrast to other cities, there is no standard type of vehicle operating in Berlin. Both vehicles from the upper and lower end of the car market may be found. Diesel is still the preferred fuel for taxis, but both hybrid-gasoline as well as natural gas powered cars may be found. Especially the usage of natural gas was subsidized in the past.

The amount of available BEV models on the market which are suitable for taxi usage has increased substantially. Volkswagen (e-Golf), Renault (Kangoo Z.E.), Nissan (Leaf), Mercedes-Benz (B-Klasse Electric Drive), Ford (Focus Electric) and Tesla (Model S), all offer potential candidates for taxicabs in different price ranges. With the exception of the Model S, all vehicles come with a nominal battery capacity of 20 to $28 \mathrm{kWh}$, of which around $80 \%$ are usable at moderate temperatures and only around $70 \%$ at $-20^{\circ} \mathrm{C}$.

There are also several case studies for designated electric taxi vehicles. Some of them focus rather on comfort, high battery capacities and ultra-fast charging [2], while others are rather proposing more light-weight concepts [1].

Calculations in this paper are based on the Nissan Leaf, mainly because it is the most popular BEV on the European market. Moreover, it has been on the market long enough so that detailed consumption statistics exist. An energy consumption of $11 \mathrm{kWh} / 100 \mathrm{~km}$ at city conditions was measured [6] as a realistic value for a Leaf without any auxiliary power consumers such as lights, radio or climate control. In every day operations, a value of $15 \mathrm{kWh} / 100 \mathrm{~km}$ at an outside temperature of $15{ }^{\circ} \mathrm{C}$ is more realistic. ${ }^{4}$ Auxiliary devices, heating and cooling further increase consumption, typically between 1 and $3 \mathrm{~kW}$, depending on the weather conditions. ${ }^{5}$

\section{Energy consumption and battery charging}

To evaluate the effects of satisfying all short-haul taxi demand in Berlin using BEVs, the whole currently operative fleet is considered. Long-distance taxi trips are generally not part of this paper, mainly because they are very rare (e.g. 20+ km long trips account for about $1 \%$ of all trips [5]; moreover, trips $50+\mathrm{km}$ long follow different taxation rules and do not count as a form of public transport. Several scenarios taking into account different outside conditions in terms of demand for taxi trips and the weather have been developed. Table 1 provides an overview about the mileage and drive times assumed $[5,10]$.

In the default scenario, all cars are able to charge at a rate of $50 \mathrm{~kW}$ under standard conditions (the rate of the currently available fast charging standards CHAdeMO and CCS), vehicles are operating 16 hours a day, split into two 8-hour shifts, and their average driving speed is $30 \mathrm{~km} / \mathrm{h}$.

\footnotetext{
4 see http://www.spritmonitor.de/de/uebersicht/33-Nissan/1296-Leaf.html?powerunit=2

5 see http://www.fleetcarma.com/electric-vehicle-heating-chevrolet-volt-nissan-leaf/
} 
Table 1 Assumptions about average daily mileage per vehicle during ordinary and busy days

\begin{tabular}{lll}
\hline & Standard demand & Increased demand \\
\hline Work time $[\mathrm{h}]$ & 16 & 16 \\
Busy mileage $[\mathrm{km}]$ & 150 & 225 \\
Idle mileage $[\mathrm{km}]$ & 75 & 75 \\
Overall mileage $[\mathrm{km}]$ & 225 & 300 \\
Average speed $[\mathrm{km} / \mathrm{h}]$ & 30 & 30 \\
Drive time $[\mathrm{h}]$ & 7.5 & 10 \\
Idle time $[\mathrm{h}]$ & 8.5 & 6 \\
\hline
\end{tabular}

It is assumed that taxis start their first shift fully charged and end the second one discharged, so additional (slow) charging may take place during off-shift time. The detailed energy consumption under different scenarios is provided in Table 2.

\subsection{Standard conditions}

With standard climate conditions (i.e. neither air conditioning nor heating in constant use) and a typical demand for taxi trips (225 km of travel distance a day, of which 70 $\mathrm{km}$ are without any customers on board) roughly $42 \mathrm{kWh}$ of electric energy per vehicle will be consumed, of which at least $26 \mathrm{kWh}$ need to be supplied by fast chargers during the day. This would require about 30 minutes of charging, separated at least into two cycles. Considering the moderate Berlin climate conditions, this scenario represents around half of the year.

\subsection{Hot and very hot summer conditions}

During hotter summer days, constant usage of air conditioning while driving will increase the overall energy usage to $57 \mathrm{kWh}$ per vehicle and day. Thus, almost 50 minutes of charging will be required per car (divided into at least three sessions). If taxi drivers keep on using air conditioning also when standing, energy consumption climbs to $70 \mathrm{kWh}$ and fast charging time to over $1 \mathrm{~h}$. The car would therefore most likely need to charge four times during a day. However, climate conditions in Berlin usually do not require such behaviour.

\subsection{Cold and very cold winter conditions}

Wintertime operations are somewhat more extreme. Battery charging is highly temperature dependent and the lower the temperature, the longer the charging process takes. Charging power may drop to $25 \mathrm{~kW}$ and below [2]. At the same time, vehicle heating increases battery usage. Heating vehicles only during drive time will raise the average daily energy consumption to $64 \mathrm{kWh}$. If charging can now only take place at $25 \mathrm{~kW}$, each vehicle would likely need to charge for almost two hours during work shifts. Should drivers require vehicle heating also during breaks, energy consumption will rise even further (106 $\mathrm{kWh}$ per vehicle), which requires a sizeable charging infrastructure. 
Table 2 Energy consumption, charger usage, charging infrastructure and costs

\begin{tabular}{|c|c|c|c|c|c|c|c|c|}
\hline Scenario & Standard & Summer & $\begin{array}{l}\text { Hot } \\
\text { Summer }\end{array}$ & Winter & $\begin{array}{l}\text { Cold } \\
\text { winter }\end{array}$ & $\begin{array}{l}\text { Cold } \\
\text { winter }\end{array}$ & $\begin{array}{l}\text { Cold } \\
\text { winter }\end{array}$ & $\begin{array}{l}\text { Cold } \\
\text { winter }\end{array}$ \\
\hline Busy day & - & - & - & - & - & + & - & + \\
\hline Fossil heating & - & - & - & - & - & - & + & + \\
\hline \multicolumn{9}{|l|}{ Driving } \\
\hline Drivetrain [kWh] & 33.75 & 33.75 & 33.75 & 33.75 & 33.75 & 45.00 & 33.75 & 45.00 \\
\hline Auxiliary [kWh] & 8.00 & 8.00 & 8.00 & 8.00 & 8.00 & 8.00 & 8.00 & 8.00 \\
\hline Heating [h] & - & - & - & 7.50 & 16.00 & 16.00 & - & - \\
\hline Heating [kWh] & - & - & - & 15.00 & 48.00 & 48.00 & - & - \\
\hline Cooling [h] & - & 7.50 & 14.00 & - & - & - & - & - \\
\hline Cooling [kWh] & - & 7.50 & 14.00 & - & - & - & - & - \\
\hline Total [kWh] & 41.75 & 56.75 & 69.75 & 64.25 & 105.75 & 117.00 & 41.75 & 53.00 \\
\hline \multicolumn{9}{|l|}{ Charging } \\
\hline $\begin{array}{l}\text { Speed }[\mathrm{kW}] \\
\text { Vehicle charging } \\
\text { time [h:mm] }\end{array}$ & $\begin{array}{l}50.00 \\
0: 32 \\
\end{array}$ & $\begin{array}{l}50.00 \\
0: 49 \\
\end{array}$ & 50.00 & $\begin{array}{l}25.00 \\
1: 56 \\
\end{array}$ & $\begin{array}{l}25.00 \\
3: 36 \\
\end{array}$ & $\begin{array}{l}25.00 \\
4: 02 \\
\end{array}$ & $\begin{array}{l}25.00 \\
1: 02 \\
\end{array}$ & $\begin{array}{l}25.00 \\
1: 29 \\
\end{array}$ \\
\hline $\begin{array}{l}\text { Chargers } \\
\text { Daily charging time } \\
\text { per charger [h:mm] }\end{array}$ & $10: 45$ & 8:09 & 5:09 & $19: 18$ & $35: 54 *$ & $40: 24 *$ & $10: 18$ & $14: 48$ \\
\hline $\begin{array}{l}\text { Utilisation ratio [\%] } \\
\text { Dispensed energy per } \\
\text { charger [kWh/day] }\end{array}$ & $\begin{array}{l}44.8 \\
537.5 \\
\end{array}$ & $\begin{array}{l}34.0 \\
407.5 \\
\end{array}$ & $\begin{array}{l}21.5 \\
257.5 \\
\end{array}$ & $\begin{array}{l}80.4 \\
482.5 \\
\end{array}$ & $149.6^{*}$ & $\begin{array}{l}168.3^{*} \\
- \\
\end{array}$ & $\begin{array}{l}42.9 \\
257.5 \\
\end{array}$ & $\begin{array}{l}61.7 \\
370.0 \\
\end{array}$ \\
\hline $\begin{array}{l}\text { Charging costs } \\
\text { Infrastructure } \\
\text { per } \mathrm{kWh}[€]\end{array}$ & 0.03 & 0.04 & 0.07 & 0.04 & - & - & 0.07 & 0.05 \\
\hline $\begin{array}{l}\text { per min }[€] \\
\text { Electricity } \\
\text { per kWh }[€]\end{array}$ & 0.03 & 0.04 & 0.06 & 0.02 & cenarios) & - & 0.03 & 0.02 \\
\hline $\begin{array}{l}\text { User costs } \\
\text { per } \mathrm{kWh}[€] \\
\text { per } \min [€]\end{array}$ & $\begin{array}{l}0.23 \\
0.19\end{array}$ & $\begin{array}{l}0.24 \\
0.20 \\
\end{array}$ & $\begin{array}{l}0.27 \\
0.22\end{array}$ & $\begin{array}{l}0.24 \\
0.10\end{array}$ & $\begin{array}{l}- \\
- \\
-\end{array}$ & $\begin{array}{l}- \\
- \\
-\end{array}$ & $\begin{array}{l}0.27 \\
0.11\end{array}$ & $\begin{array}{l}0.25 \\
0.10 \\
\end{array}$ \\
\hline
\end{tabular}

* Infeasible charging time 


\subsubsection{Busy days}

Extreme winter days with constant heating combined with a city-wide high taxi demand (resulting in an average driving distance of $300 \mathrm{~km}$ per vehicle) would require roughly $117 \mathrm{kWh}$ of energy per vehicle. However, even then, wait time is lower than the required charge time of more than $4 \mathrm{~h}$.

This means that vehicles have technically enough time to charge, given the charging infrastructure is well developed. The occurrence of such days is somewhat predictable in advance, so drivers may plan their charging behaviour accordingly.

\subsubsection{Alternative heating}

Most wintertime charging problems could be solved by using a fossil heating unit. In this case, vehicle operations would only be carbon neutral if bio-fuels are used. With less roughly half a litre of fuel per hour ${ }^{6}$, emissions would still be negligible. Each vehicle's electric energy consumption would lower to $42 \mathrm{kWh}$ (as in the standard scenario), of which $26 \mathrm{kWh}$ would need to be charged during the day. At low temperatures, this would lower the average charging time per vehicle to 1:05 h. Under increased demand, when energy consumption rises to $53 \mathrm{kWh}$, daily charge time would still be just under two hours. Such charging times are manageable. The use of alternative heating sources can definitely reduce the size of the charging infrastructure needed.

\section{Charging infrastructure}

\subsection{Size}

As described in the previous section, an electric taxi fleet will require a city-wide fast charging infrastructure. At the time of writing, Berlin-wide there are less than ten fast chargers available to the public. This number will certainly increase over the next years, but is not likely to be sufficient any time soon to satisfy the charging demand for a whole taxi fleet. Therefore a dedicated fast charging network exclusively for taxis might be desirable. Chargers could be positioned at taxi ranks, allowing taxis to use idle time for charging. A practical consequence is that a pre-booking of charging slots is easily possible. Also the whole charging infrastructure would need to be financed by taxi usage.

Accurate estimation of the optimal size of the charging infrastructure is a challenging task. As the overall electric taxi dispatching process is highly stochastic in terms of both time and space, it requires carrying out simulation in order to take into account the mutual relationships between taxi demand, taxi supply and charger availability. Such detailed analysis is, however, beyond the scope of this paper and is the subject of ongoing research.

6 see http://www.gizmag.com/bio-ethanol-powered-heater-volvo-c30/18250/ 
It is assumed that there are 720 chargers available exclusively for taxis, which gives one charger per 10 vehicles. The chargers are allocated to taxi ranks proportionally to the ranks' occupancy. As in Section 4, the analysis is carried out for a single day and for each of the defined scenarios (e.g. summer, winter, etc.). Table 2 presents the average utilisation of chargers. Since taxi demand is much higher in the morning and in the afternoon than during the rest of the day, an utilisation below $100 \%$ does not mean that there will not be taxis waiting in queues for charging. Also the spatial variability of taxi demand over time may lead to temporal shortages of available chargers at certain taxi ranks. Therefore, the utilisation level of $80 \%$ (the winter scenario) may not prevent such queues.

According to Table 2, one may speculate that with 720 fast chargers (the ratio of 10 vehicles per charger) dispatching of electric taxis is feasible all over the year except for winter. In order to make the electric fleet operational also during that period, either the vehicles should be equipped with external heaters or the number of chargers be doubled or even tripled.

\subsection{Costs}

At current prices, the costs for a combined CHAdeMO/CCS fast charger are roughly priced at $18500 €$ per unit (including the set-up). Assuming a 5-year deprecation and the annual maintenance cost of $2500 €$, the daily cost of a fast charger equals $17 €$. With the ratio of 10 taxis per charger and the use of external heating, the consumption-based infrastructure charge (cf. Table 2, lower part) is predicted to be between 0.03 and $0.07 \frac{\epsilon}{k W h}$, depending on the consumption scenario. Taking into account the energy price of $0.20 \frac{\epsilon}{k w h}$, the cost of charging oscillate between 0.23 and $0.27 \frac{\epsilon}{k W h}$.

From the infrastructure provider's point of view, it is preferable to charge users on a time base in order to grant a high throughput of customers at the chargers. This would provide an incentive for drivers not to charge longer than efficient (fast chargers slow down once $80 \%$ SOC is reached). Moreover, the risk of weather or vehicle-dependent slower charging process would lie on the customers' side. In this case, the rate should be $0.10 \frac{\epsilon}{\min }$ in winter (given two times slower charging) and around $0.20 \frac{\epsilon}{\text { min }}$ during the rest of the year (fast charging).

It should be noted that the calculation above is based on the infrastructure and maintenance costs of a single charger. Hence scale effects are not included but would most likely lead to lower costs.

\section{Operating cost comparison}

From an operator's point of view, the decision whether to use a BEV fleet or to continue to use a conventional fleet is mostly an economic one. As mentioned in Section 3, there are several BEVs available in the same pricing range as similar hybrid electric vehicles (HEV), such as the Toyota Prius. 
Considering the lower price segment of cars, possible BEV taxi operators will most likely see HEV as an alternative in fleet planning. Table 3 provides an overview of annual costs for both car types. An average electric taxi with an annual mileage of $75000 \mathrm{~km}$ will consume approximately $20 \mathrm{MWh}$. Based on the energy price of $0.20 \frac{\epsilon}{k W h}$, and the annual cost of a single charger (including depreciation) of $6200 €$, the annual cost of energy per vehicle totals to $4620 €$.

With the average consumption of a Toyota Prius in inner-city traffic being roughly $5.5 \frac{l}{100 \mathrm{~km}}$ and fuel prices of around $1.55 \frac{\epsilon}{l}$, the example above with an annual mileage of $75000 \mathrm{~km}$ accumulates to $6390 €$ of fuel costs per year. Thus the energy-wise monetary saving of a BEV is around $28 \%$.

However, BEV manufacturers generally do not grant a warranty for the car's battery for more than $150000 \mathrm{~km} .{ }^{7}$ It is therefore likely that the battery needs a replacement every second year.

Since Nissan offers a battery replacement for a Leaf battery for roughly $5000 €^{8}$, the annual cost of a battery is $2500 €$. A longer warranty time or a fleet wide battery replacement agreement could bridge this gap. On the other hand, the BEV will require substantially less engine-related maintenance. The exact savings in this field are hard to predict, as they are highly vehicle- and owner-dependent. For New York City the saving was estimated at more than $3000 \$$ a year [12].

For a HEV taxi, engine-related costs of roughly $1000 €$ a year need to be covered. ${ }^{9}$ For a BEV, this sums up only to roughly $150 € .{ }^{10}$ The remaining operational costs should be roughly comparable for both $\mathrm{BEV}$ and $\mathrm{HEV}$, as are procurement costs of the vehicle itself.

Table 3 Annual operating cost comparison of BEV and HEV

\begin{tabular}{llc}
\hline & BEV & HEV \\
\hline Annual mileage $[\mathrm{km}]$ & \multicolumn{2}{c}{75,000} \\
Energy cost $[€]$ & 4,620 & 6390 \\
Battery cost $[€]$ & 2,500 & \\
Engine maintenance $[€]$ & 150 & 1,000 \\
\hline Overall operating costs $[€]$ & 7,270 & 7,390 \\
\hline
\end{tabular}

\section{Conclusion}

A transition of Berlin taxi vehicles to an all-BEV-fleet using currently available infrastructure and vehicles will take considerable effort in organisational and financial terms. To warrant a smooth service, about one $50-\mathrm{kW}$ fast charger per 10 taxis would need to be installed in the city. Refinancing them by usage should be based on the time spent at a charger rather than the energy consumed. Winter operations will result

\footnotetext{
${ }^{7}$ see http://www.nissan.de/DE/de/vehicle/electric-vehicles/leaf/prices-and-equipment/services-warranty.html

8 see https://transportevolved.com/2014/12/07/nissan-announces-leaf-battery-replacement-program-europe-cheaper-youd-think/

9 see http://www.taxiforum.de/forum/viewtopic.php?t=8332

10 see http://www.goingelectric.de/forum/nissan-leaf-allgemeines/noetige-wartung-pflege-nissan-leaf-ausserhalb-garantie-t1600.html
} 
in a peak in energy consumption and charger usage. It seems advisable to invest in fossil-based heating units rather than heating vehicles using battery power.

From the taxi operator's point of view, given the state-of-the art technology, using BEVs as taxis will only pay off if some kind of agreement concerning the battery life is in place, or the energy price would drop significantly; otherwise the service will need to be subsidised.

\section{Acknowledgement}

The authors would like to thank the Einstein foundation for co-funding this paper.

\section{References}

Date of access for all internet references provided in footnotes: 25.02.2015.

1. Adaptive City Mobility: Project CITY eTAXI, 2014, see http://www.adaptive-citymobility.de/

2. Andersson, D., Carlsson, D.: Measurements of ABB's prototype fast charging station for electric vehicles. Master's thesis, University of Technology Gothenburg, (2012)

3. Bender, S. Pannirsilvam, V., Khoo, R.: Concept of an electric taxi for tropical megacities. In 3rd Conference on Future Automotive Technology (CoFAT'14) (2014) 4. Bischoff, J., Maciejewski, M.: Agent-based simulation of electric taxicab fleets. Transportation Research Procedia, vol 4 pp. 191-198 (2014).

5. Bischoff, J., Maciejewski, M., Sohr, A.: Analysis of Berlin's taxi services by exploring GPS traces. Accepted for MT-ITS 2015

6. BZP - Deutscher Taxi- und Mietwagenverband e.V.: Zahlen über den Taxi- und Mietwagenverkehr 2013/2014, Berlin (2014)

7. Faria, R., Moura, P., Delgado, J., Almeida, A.: A sustainability assessment of electric vehicles as a personal mobility system. Energy Conversion and Management Journal, vol. 61 (2012)

8. Horni, A., Nagel, K., Axhausen,K.W. (editors): The Multi-Agent Transport

Simulation MATSim, forthcoming (2015)

9. Lieven, T., Mühlmeier, S., Henkel, S., Waller, J.F.: Who will buy electric cars? An empirical study in Germany, Transportation Research Part D: Transport and Environment, vol. 16(3), pp.236 - 243 (2011)

10. Maciejewski, M., Bischoff, J.: Large-scale microscopic simulation of taxi services, submitted to ANT2015.

11. Michal, M.: Dynamic transport services. In Horni et al. [8], pp. forthcoming.

12. NYC Taxi \& Limousine commission: Take charge - a roadmap to electric New York City taxis Technical report, The Mayors Long-Term Electric Taxi Task Force (2013) 